Artículo científico

Volumen 32(1):45-62. Enero-abril, 2021

e-ISSN 2215-3608, doi:10.15517/am.v32i1.41333

https://www.revistas.ucr.ac.cr/index.php/agromeso

\title{
Perfil mineral sérico de vacas Holstein en lactación en sistemas mixtos de estabulación-pastoreo $^{1}$
}

\section{Serum mineral profile of lactating Holstein cows in mixed indoor-grazing systems}

\author{
Ernesto Morales-Almarázz, Rodolfo Vieyra-Alberto ${ }^{3}$, Ignacio Arturo Domínguez-Vara², Felipe López-González, , \\ Carlos Manuel Arriaga-Jordán ${ }^{4}$, Juan Edrei Sánchez-Torres ${ }^{2}$
}

1 Recepción: 13 de mayo, 2020. Aceptación: 22 de septiembre, 2020. Este trabajo formó parte de una tesis de licenciatura "Concentración mineral y parámetros productivos de bovinos lecheros con distintos momentos de pastoreo en el altiplano de México", y financiado por la Universidad Autónoma del Estado de México.

2 Universidad Autónoma del Estado de México. Facultad de Medicina Veterinaria y Zootecnia. Departamento de Nutrición Animal. Instituto Literario Oriente. No. 100. C.P. 50000. Toluca, Estado de México, México. Autor para la correspondencia: emoralesa@uaemex.mx (http://orcid.org/0000-0003-0675-2193); igy92@hotmail.com (http://orcid.org/0000-0001-9718-8318), edreie@yahoo.com.mx (https://orcid. org/0000-0002-3179-2536).

3 Universidad Autónoma del Estado de Hidalgo. Instituto de Ciencias Agropecuarias. Área Académica de Medicina Veterinaria y Zootecnia. Rancho Universitario, Av. Universidad km 1 Exhacienda de Aquetzalpa, C.P. 43600 Tulancingo, Hidalgo, México. rodolfo_vieyra@uaeh. edu.mx (https://orcid.org/0000-0001-5889-1203).

4 Universidad Autónoma del Estado de México. Instituto de Ciencias Agropecuarias y Rurales. Instituto Literario 100, C.P. 50000, Toluca, Estado de México, México. flopezg@uaemex.mx (http://orcid.org/0000-0001-7769-3755), cmarriagaj@uaemex.mx (https://orcid.org/00000002-6140-0847).

\section{Resumen}

Introducción. Los minerales juegan un papel muy importante en la nutrición, porque son necesarios para la biosíntesis de nutrientes esenciales. Objetivo. Evaluar el estado mineral en suero sanguíneo, el consumo de minerales y la producción de leche de vacas Holstein en pastoreo suplementadas con distintos niveles de alimento concentrado y tiempo de permanencia en la pradera en el valle de Toluca, México. Materiales y métodos. Se realizaron dos experimentos con un diseño de cuadro Latino 3x3 cada uno en la Universidad Autónoma del Estado de México, realizados en primavera-verano de 2011-2012. En el experimento uno se evaluó el nivel de concentrado en la dieta (3, 5 y $8 \mathrm{~kg} \mathrm{día}^{-1}$ ) en vacas pastoreando; en el experimento dos se evaluaron tres tiempos de permanencia en la pradera (ocho horas continuas; dos tiempos de cuatro horas post-ordeño; y doce horas). En ambos experimentos se ofertó ensilado de maíz a libre consumo en el corral. En suero sanguíneo y alimentos se les midió la concentración de Ca, $\mathrm{P}, \mathrm{Mg}, \mathrm{K}, \mathrm{Na}, \mathrm{Cu}, \mathrm{Fe}$ y $\mathrm{Zn}$. Se realizaron análisis de correlación simple y de regresión múltiple para las variables de estudio. Resultados. El nivel de concentrado y el tiempo de permanencia en la pradera afectaron $(\mathrm{p}<0,05)$ el consumo de la mayoría de los minerales; no se cubrieron los requerimientos de $\mathrm{Ca}, \mathrm{P}, \mathrm{Mg}, \mathrm{K}$ y $\mathrm{Zn}$, y hubo exceso de Fe. Independientemente de la estrategia de alimentación, el contenido de minerales en suero sanguíneo de los bovinos fue adecuado para $\mathrm{P}, \mathrm{Na}, \mathrm{Cu}$ y Fe; marginal de $\mathrm{Ca}$, deficiente en $\mathrm{Mg}$ y $\mathrm{Zn}$; y hubo exceso de $\mathrm{K}$. Conclusiones. El consumo de minerales no fue determinante para predecir la concentración de minerales en suero sanguíneo de vacas lecheras, sin embargo, mostró influencia sobre la producción de leche de vacas bajo dos sistemas de producción mixta pastoreo-estabulación.

Palabras clave: pradera, tiempo de pastoreo, niveles de concentrado, consumo mineral, suero sanguíneo. 


\begin{abstract}
Introduction. Minerals play a very important role in nutrition; because they are necessary for the biosynthesis of essential nutrients. Objective. To evaluate the mineral status in blood serum, mineral consumption and milk production of grazing Holstein cows supplemented with different levels of concentrated feed and time spent in the meadow of Toluca valley, Mexico. Materials and methods. Two experiments were carried out with a $3 \times 3$ Latino square design each at the Universidad Autónoma del Estado de México, carried out in the spring-summer of 20112012. In experiment one, the level of concentrate in the diet $\left(3,5\right.$ and $\left.8 \mathrm{~kg} \mathrm{day}^{-1}\right)$ was evaluated in grazing cows; in experiment two, three times of permanence in the prairie were evaluated (eight continuous hours; two times of four hours post-milking; and twelve hours). In both experiments, corn silage ad libitum was offered for free consumption in the pen. The concentration of $\mathrm{Ca}, \mathrm{P}, \mathrm{Mg}, \mathrm{K}, \mathrm{Na}, \mathrm{Cu}, \mathrm{Fe}$, and $\mathrm{Zn}$ was measured in blood serum and foodstuffs. Simple correlation and multiple regression analysis were performed for the study variables of mineral intake, milk production, and minerals in blood serum. Results. The level of concentrate and the time spent in the prairie affected $(\mathrm{P}<0,05)$ of the consumption of most of the minerals; the $\mathrm{Ca}, \mathrm{P}, \mathrm{Mg}, \mathrm{K}$, and $\mathrm{Zn}$ requirements were not met, and there was excess $\mathrm{Fe}$. Regardless of the feeding strategy, the bovine blood serum mineral content was adequate for $\mathrm{P}, \mathrm{Na}, \mathrm{Cu}$, and $\mathrm{Fe}$; marginal for $\mathrm{Ca}$, deficient in $\mathrm{Mg}$ and $\mathrm{Zn}$; and there were excess of $\mathrm{K}$. Conclusion. The consumption of minerals was not decisive to predict the concentration of minerals in the blood serum of dairy cows, however, it showed influence on the milk production of cows under two mixed grazing-stallproduction systems.
\end{abstract}

Keywords: prairie, grazing time, concentrate levels, mineral consumption, blood serum.

\title{
Introducción
}

Los minerales son muy importantes en la nutrición, ya que son necesarios para la biosíntesis de nutrientes esenciales (Church \& Pound, 1987). La producción animal subóptima se debe a la insuficiencia de energía, proteína, enfermedades parasitarias o infecciosas y defectos genéticos, sin embargo, cuando estos problemas se corrigen se aumenta la importancia de la nutrición mineral (Minson, 1990; Suttle, 2010). Así, la nutrición mineral adecuada es el factor con el mayor potencial y con el menor costo para incrementar la producción de leche en pastoreo (McDowell et al., 1993).

En bovinos lecheros en pastoreo, cuya ración se basa forrajes, en su mayoría pastos nativos o residuos de cosechas, aunque también utilizan alimentos concentrados (Arriaga-Jordan et al., 2001) en determinadas circunstancias, no cubren sus requerimientos o pueden tener exceso de algún mineral que comprometan su salud y producción (Morales-Almaráz et al., 2007).

A medida que las plantas se desarrollan, el contenido mineral disminuye, debido a un proceso natural de dilución (Fleming, 1973) y a la translocación de nutrientes hacia el sistema radicular (Tergas \& Blue, 1971). Cuando las áreas fotosintéticas de la planta aumentan, la producción de materia seca sobrepasa la fracción mineral, resultando en una disminución de la materia inorgánica (Fleming, 1973). Según lo reportado por CastroHernández et al. (2017), hubo un aumento lineal del contenido de materia seca con el avance de la edad al corte de forraje raigras (Lolium perenne), mientras que el contenido de la materia orgánica disminuyó. El intervalo de corte afectó al contenido mineral y la concentración de P, K, Ca, Mg y Zn fueron insuficientes para satisfacer los requerimientos de vacas en lactación (Castro-Hernández et al., 2017). Contrariamente, un exceso de Ca en el suero de vacas lecheras contrastó con la carencia del mineral en el forraje, lo cual fue más acentuado en la época de lluvias (Morales-Almaráz et al., 2007). La accesibilidad, un factor inherente a la biodisponibilidad de un mineral, es afectada por la forma química del mineral presente y sus interacciones con agonistas y antagonistas en el alimento o en el intestino (Suttle, 2010). 
En las investigaciones realizadas en distintas zonas del Valle de Toluca, México (Castro-Hernández et al., 2017; Domínguez-Vara \& Huerta-Bravo, 2008; Morales-Almaráz et al., 2007), se han observado amplias variaciones en el contenido de minerales de forrajes destinados al pastoreo del ganado lechero y ovino, lo cual ha sido asociado al efecto de las condiciones climáticas, época del año y al estado de madurez de la planta. La presencia de desequilibrios de minerales, principalmente, la carencia de $\mathrm{Cu}$ en forraje, suelo y suero de ovinos, está asociado al exceso de Fe (Domínguez-Vara \& Huerta-Bravo, 2008). La deficiencia de $\mathrm{Cu}$ y $\mathrm{Zn}$ en suero de leche de bovinos especializados en producción lechera fue observada por Morales-Almaráz et al. (2007).

En el Valle Central de México, investigaciones en unidades de producción (UP) de vacas y ovinos, han sido principalmente enfocadas a evaluar el contenido mineral en el suelo, alimentos y suero sanguíneo del animal (Domínguez-Vara \& Huerta-Bravo, 2008; Morales-Almaráz et al. 2007), pero no ha sido considerada la evaluación de la relación del estado mineral del animal con su desempeño (productivo, reproductivo y sanitario). En aquellos casos solo se infiere que los desbalances de minerales en los alimentos y en el suero sanguíneo de los animales podría afectar su productividad y salud, más tal suposición no fue evaluada per se. El muestreo de sangre es deseable por la dificultad para valorar el estado mineral del animal desde la evaluación de la dieta (Herdt \& Hoff, 2011). Existen múltiples factores influyentes que podrían afectar los valores de minerales en suero sanguíneo. Aunque la nutrición está entre estas influencias, determinarla en una situación dada podría ser difícil (Herdt \& Hoff, 2011). Las pruebas de suero sanguíneo o sangre para la concentración mineral total es un medio potencialmente valorable para la evaluación de estado nutricional mineral, y, generalmente, es más práctico que otros métodos. Sin embargo, está sujeto a muchas limitaciones y los resultados deben ser interpretados con cautela.

En una investigación se observó correlación entre el contenido de $\mathrm{Cu}$ y $\mathrm{Mg}$ en suero sanguíneo de vacas en lactación con la frecuencia de diarreas, así como relación entre el contenido de Zn en suero sanguíneo y la tasa de concepción y trastornos uterinos. Además, la incidencia de mastitis en las vacas se correlacionó con el nivel de K en suero (Meda-Alducin, 2017).

El diagnóstico es el medio inmediato, basado en el análisis de los componentes suelo, planta, animal y otras fuentes de minerales (McDowell \& Arthington, 2005), para distinguir la existencia y prevalencia de minerales en los animales, aún en aquellos sin manifestaciones claras o clínicas de tal situación o deficiencia (Kincaid, 1999). Además, la información en nutrición de ganado lechero en pequeña escala está altamente dirigida a la evaluación del aporte de constituyentes mayoritarios de la dieta (energía, proteína y fibra) y en menor medida al estudio de minerales, los cuales resultan determinantes en el metabolismo de aquellos componentes e importantes en la salud y vida productiva y reproductiva del animal. Se sabe que otros factores, además de la nutrición, afectan la concentración de minerales en suero sanguíneo. En específico, las fuerzas homeastáticas modulan la concentración sérica de la mayoría de los minerales dentro de un rango de puntos de ajuste homeostáticos que varían en amplitud entre los distintos minerales (Herdt \& Hoff, 2011).

Conocer el perfil mineral de los bovinos lecheros es fundamental para evaluar el estado nutricional, asociarlo al desempeño productivo (consumo de alimento y producción de leche) en condiciones de pastoreo.

El objetivo del presente trabajo fue evaluar el estado mineral en suero sanguíneo, el consumo de minerales y la producción de leche de vacas Holstein en pastoreo suplementadas con distintos niveles de concentrado y tiempo de permanencia en la pradera.

\section{Materiales y métodos}

Dos experimentos fueron realizados en primavera-verano de 2011 y 2012 en la Facultad de Medicina Veterinaria y Zootecnia de la Universidad Autónoma del Estado de México, ubicada en el campus universitario "El Cerrillo" Toluca, México, a 19²4' 48" latitud norte y 99 40’ 45" longitud oeste, y una altura de $2632 \mathrm{msnm}$ (Instituto Nacional de Estadística y Geografía, 2007). 
Las estrategias de alimentación evaluadas en la presente investigación, fueron establecidas considerando que la alimentación prevaleciente en los sistemas de producción de leche en el altiplano central de México, está basada en el pastoreo complementario al uso de forrajes conservados y de alimentos concentrados suministrados en el corral (Arriaga-Jordán et al., 2001). Así, una de estas estrategias evaluadas fue considerada representativa de la práctica común de la alimentación animal en el área de estudio, misma que permaneció con el manejo alimenticio del hato experimental, independientemente de la duración de esta investigación, y fue común en ambos experimentos.

Las estrategias de alimentación del ganado lechero en pastoreo estuvieron basadas en el suministro de distintos niveles de alimento concentrado (experimento uno) y distintos tiempos de permanencia en la pradera (experimento dos), para determinar su influencia en el consumo de minerales (Ca, P, Mg, K, Na, Cu, Fe y Zn) y la concentración mineral en suero sanguíneo del animal.

\section{Animales y tratamientos}

\section{Experimento uno}

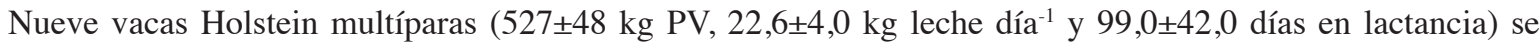
usaron en tres periodos experimentales, de catorce días de adaptación y cinco días de medición, en un diseño de cuadrado latino 3x3, replicado tres veces. La alimentación de las vacas estuvo basada en un sistema mixto, con acceso a la pradera, complementado con ensilado de maíz y concentrado en el establo. Diariamente se realizaron dos ordeños, a las 06:00 h (am) y 15:00 h (pm).

El alimento concentrado contenía $18 \%$ de proteína cruda y 2,0 Mcal de $\mathrm{EN} \mathrm{kg}^{-1} \mathrm{MS}$ para lactancia (ENL), y fue elaborado con sorgo (486,7 $\left.\mathrm{g} \mathrm{kg}^{-1} \mathrm{MS}\right)$, pasta de soya (200,4 $\left.\mathrm{g} \mathrm{kg}^{-1} \mathrm{MS}\right)$, canola (147,5 $\left.\mathrm{g} \mathrm{kg}^{-1} \mathrm{MS}\right)$, salvado de trigo $\left(146,7 \mathrm{~g} \mathrm{~kg}^{-1} \mathrm{MS}\right)$ y premezcla de minerales $\left(18,7 \mathrm{~g} \mathrm{~kg}^{-1} \mathrm{MS}\right.$; Fosforysal $120 \mathrm{~L} \circledast$, que contiene: $120 \mathrm{~g}$ de $\mathrm{P}$, $1,33 \mathrm{~g}$ de $\mathrm{Cu}, 2 \mathrm{~g}$ de Fe, $10 \mathrm{~g}$ de $\mathrm{Mg}, 11 \mathrm{mg}$ de Co, 0,080 $\mathrm{g}$ de I, $4 \mathrm{~g}$ de Zn, 12,5 g de S, 0,022 g de Se, $120 \mathrm{~g}$ de $\mathrm{Ca} ; 200 \mathrm{~g}$ de sal, $4 \mathrm{~g}$ de $\mathrm{Mn}, \mathrm{y} 0,013 \mathrm{~g}$ de Co ).

El alimento concentrado ( $\mathrm{kg} \mathrm{MS} \mathrm{vaca}{ }^{-1}$ día $^{-1}$ ) se proporcionó asociado al tiempo de acceso a la pradera, conformando los siguientes tratamientos: 1) 7,2 kg de concentrado (8 c) con acceso a la pradera de 07:00 a 15:00 h; 2) 4,5 kg de concentrado (5c) con acceso a la pradera de 07:00 a 15:00 h y de 16:00 a 20:00 h; 3) 2,7 kg de concentrado (3c) con acceso a la pradera de 07:00 a 15:00 h y de 16:00 a 20:00 h.

En la estabulación, el concentrado se ofreció a las 16:00 y 20:00 h para el tratamiento 1, y a las 20:00 y 24:00 h para los tratamientos 2 y 3 . El ensilado de maíz se ofreció a libre acceso en los mismos tiempos.

El manejo diario de las vacas en la pradera fue el siguiente: las nueve vacas fueron llevadas a la pradera donde permanecieron juntas de 7:00 a 15:00 h. A las 16:00 h, las vacas en 8c fueron estabuladas y los grupos 5c y $3 \mathrm{c}$ regresaron a la pradera donde permanecieron hasta las 20:00 h; posteriormente, fueron estabuladas.

El tratamiento 1 corresponde al manejo alimenticio comúnmente utilizado en la unidad de producción, refleja lo aplicado en los sistemas de producción de leche que utilizan el pastoreo y la complementación alimenticia en corral con forrajes conservados y alimentos concentrados comerciales.

El área de pastoreo estuvo acorde con una asignación de pasto de $25 \mathrm{~kg}$ de MS día ${ }^{-1}$ por vaca. Para ello, se determinó la producción de biomasa pre-pastoreo mediante el corte del forraje con cuadrantes $\left(\mathrm{de} 0,25 \mathrm{~m}^{2}\right)$ a ras del suelo, se pesó y homogenizó el material fresco, se tomó la muestra y se secó a $60{ }^{\circ} \mathrm{C}$ en estufa de aire forzado. La superficie de pastoreo designada se ajustó cada día durante la etapa de medición en cada periodo con ayuda de un cerco eléctrico. 


\section{Experimento dos}

Se utilizaron seis vacas multíparas de raza Holstein $\left(615 \pm 36 \mathrm{~kg}\right.$ PV; $22,7 \pm 4,8 \mathrm{~kg}$ leche día $\left.{ }^{-1}\right)$, en tres periodos experimentales de 15 días cada uno (10 días de adaptación y 5 días de medición), en un diseño de cuadro latino $3 \times 3$ repetido dos veces.

La alimentación fue similar a la descrita en el experimento 1 y acorde a un sistema mixto, estuvo constituida de pastoreo y la complementación con alimento concentrado y ensilado de maíz en la estabulación. Diariamente se suministraron 4,48 kg de MS de concentrado por vaca con la misma composición de ingredientes y similar aporte nutricional a lo descrito en el experimento 1. Adicionalmente, en la estabulación se ofertó ensilado de maíz ad libitum.

Los tratamientos evaluados fueron: 1) $8 \mathrm{~h}$ de acceso a la pradera en la mañana (8h); 2) $4 \mathrm{~h}$ de acceso a la pradera en la mañana y $4 \mathrm{~h}$ en la tarde $(4+4 \mathrm{~h})$; 3$) 12 \mathrm{~h}$ de acceso a la pradera, $8 \mathrm{~h}$ en la mañana y $4 \mathrm{~h}$ en la tarde (12h). El tratamiento 3 de este experimento, coincide con el tratamiento 2 indicado en el experimento 1.

\section{Mediciones y muestreo}

En los dos experimentos, el pastoreo fue en praderas polífitas de 2,5 ha. Las especies vegetales predominantes fueron Lolium perenne, Trifolium repens, Festuca arundinacea, Dactylis glomerata y Pennisetum clandestinum. Las praderas fueron fertilizadas con $50 \mathrm{~kg}$ urea ha- ${ }^{-1}$ cada mes. En las praderas y en la estabulación las vacas tuvieron libre acceso al agua de bebida.

En las etapas de medición en ambos experimentos, diariamente se midió el consumo de los alimentos en el corral (ensilado de maíz y concentrado), así como la producción de leche al momento del ordeño de cada vaca. El consumo de alimento en la estabulación se estimó por diferencia de la oferta y rechazo.

El consumo de pasto se determinó mediante el cálculo del requerimiento de energía neta para lactación (ENL) del ganado lechero (National Research Council, 2001) y el aporte de energía neta de los alimentos consumidos en el establo (Macoon et al., 2003). El contenido de EN del pasto, del ensilado de maíz y del alimento concentrado se calculó a partir del contenido de fibra en detergente ácido (FDA) (Menke \& Steingass, 1988).

El ensilado de maíz se muestreó diariamente y el concentrado una vez por cada periodo experimental. La pradera fue muestreada utilizando la técnica de pastoreo simulado en el primer día de la fase de medición (WayneCook, 1964). Todas las muestras se conservaron para su posterior análisis en el laboratorio.

Al inicio y al final de cada etapa de medición, se tomó de la vena caudal una muestra de sangre (14 ml, aproximadamente), se dejó reposar por $10 \mathrm{~h}$ para separar el paquete celular, una vez pasado este tiempo, el suero sanguíneo se conservó en tubos cónicos de plástico con capacidad de $2 \mathrm{ml}$ a temperatura de congelación $\left(-20^{\circ} \mathrm{C}\right)$.

\section{Análisis de laboratorio}

Las muestras de los alimentos (ensilado de maíz, alimento concentrado y pasto) fueron secadas con estufa de aire forzado a $60{ }^{\circ} \mathrm{C}$ por $24 \mathrm{~h}$, se molieron con malla de $2 \mathrm{~mm}$.

La determinación de minerales en alimentos se realizó por duplicado, pesando $1 \mathrm{~g}$ de muestra en tubos de vidrio, se adicionaron $8 \mathrm{ml}$ de ácido nítrico $\left(\mathrm{HNO}_{3}, 65 \%\right.$ pureza) y $4 \mathrm{ml}$ de ácido perclórico $\left(\mathrm{HClO}_{4}, 72 \%\right.$ pureza $)$, se dejaron reposar por $12 \mathrm{~h}$ (pre-digestión). Pasado este tiempo se colocaron los tubos en el digestor y se calentó hasta $150{ }^{\circ} \mathrm{C}$ por $45 \mathrm{~min}$, hasta que desaparecieron los humos pardos, se aumentó la temperatura a $210{ }^{\circ} \mathrm{C}$ por 60 min más, el final de la reacción estuvo marcada por la aparición de vapores blancos densos característicos del $\mathrm{HClO}_{4}$, se dejó enfriar, se agregaron $20 \mathrm{ml}$ de agua destilada a los tubos y se filtraron con papel de poro fino en matraces volumétricos de $50 \mathrm{ml}$, el aforo final fue con agua destilada. Esta dilución fue de 1:50 (Allan, 1971). 
Las muestras de suero sanguíneo se descongelaron a temperatura ambiente, se tomó una alícuota de $2 \mathrm{ml}$ y se adicionaron $8 \mathrm{ml}$ de ácido tricloroacético al $10 \%$, se agitaron en vortex por $60 \mathrm{~s}$ y se dejó reposar $10 \mathrm{~min}$, se centrifugaron a $2500 \mathrm{rpm}$ por $10 \mathrm{~min}$, se conservó la parte líquida en tubos de plástico limpios. Esta dilución fue de 1:5 (Fick et al., 1979).

La cuantificación de $\mathrm{Ca}, \mathrm{Mg}, \mathrm{Cu}, \mathrm{Fe}$ y Zn, se realizó por espectrofotometría de absorción atómica (Perkin Elmer, 3110), el K y Na por flamómetro (Corning, 410) (Fick et al., 1979), y el P por colorimetría en espectrofotómetro de luz ultravioleta (Perkin Elmer, modelo Génesis 20) (Harris \& Popat, 1954).

\section{Análisis estadístico}

La ingestión de alimento, el consumo de minerales y el contenido de minerales en suero sanguíneo de los bovinos en ambos experimentos, se sujetaron a análisis de varianza, utilizando el procedimiento MIXED (SAS Institute Inc., versión 9.0) bajo el siguiente modelo estadístico: $\mathrm{Y}_{\mathrm{ijkl}}=\mu+\mathrm{C}_{\mathrm{i}}+\mathrm{V}_{\mathrm{j}(\mathrm{i})}+\mathrm{P}_{\mathrm{k}}+\mathrm{T}_{1}+\mathrm{E}_{\mathrm{ijk} \mathrm{l}}$; donde $\mathrm{Y}_{\mathrm{ijk}}=$ variable respuesta: $\mu=$ media general; $\mathrm{C}_{\mathrm{i}}=$ efecto aleatorio del cuadro; $\mathrm{V}_{\mathrm{j}(\mathrm{i})}=$ efecto aleatorio de la vaca dentro del cuadro; $\mathrm{P}_{\mathrm{k}}=$ efecto aleatorio del periodo $(1,2,3) ; \mathrm{T}_{1}=$ efecto fijo del tratamiento (niveles de concentrado o tiempos de permanencia en la pradera); $\mathrm{E}_{\mathrm{ijk} \mathrm{l}}=$ error residual.

Se designaron diferencias con significancia de $\mathrm{p} \leq 0,05$, se aplicó la prueba de Tukey para la comparación de medias.

Se realizó análisis de correlación de Pearson, así como regresión múltiple por el procedimiento stepwise de SAS entre las variables de consumo de minerales con el contenido de estos en suero sanguíneo (SAS Institute Inc., versión 9.0).

\section{Resultados}

El contenido mineral de los alimentos consumidos por las vacas durante los dos experimentos se observa en el Cuadro 1.

El consumo diario de materia seca de las vacas en ambos experimentos es presentado en el Cuadro 2. El concentrado ofrecido a las vacas fue consumido en su totalidad en ambos experimentos.

El tratamiento 8c mostró la mayor $(\mathrm{p}<0,05)$ ingestión de MS en estabulación con respecto a los otros tratamientos, debido al mayor consumo de concentrado principalmente. El consumo de pasto se incrementó $(\mathrm{p}<0,05)$ con la disminución del nivel de concentrado, en el tratamiento $3 \mathrm{c}$ el consumo de pasto fue 2 y 4,5 veces mayor que los tratamientos $5 \mathrm{c}$ y $8 \mathrm{c}$, respectivamente. Así, el consumo diario de MS total fue mayor $(\mathrm{p}<0,05)$ y estadísticamente igual en los tratamientos $8 \mathrm{c}$ y $3 \mathrm{c}$, en comparación con el tratamiento $5 \mathrm{c}$. El consumo de ensilado de maíz fue diferente $(p<0,05)$ entre tratamientos en el experimento 2 (Cuadro 2), fue mayor en las vacas que permanecieron ocho horas continuas en la pradera, y estadísticamente igual cuando se asignaron dos tiempos de cuatro horas en la pradera; las vacas del tratamiento $12 \mathrm{~h}$ mostraron menor consumo de ensilado, estas diferencias se debieron al menor tiempo que estuvieron las vacas en estabulación donde disponían de ensilado de maíz a libre acceso. Por el contrario, el consumo de pasto fue mayor $(\mathrm{p}<0,05)$ cuando más tiempo permanecieron las vacas en la pradera.

Las vacas en el tratamiento $12 \mathrm{~h}$ consumieron 2,5 veces más pasto que el tratamiento $8 \mathrm{~h}$, y 1,8 veces más que $4+4 h$; no hubo diferencia $(\mathrm{p}<0,05)$ en el consumo de pasto entre vacas que permanecieron ocho horas continuas o divididas en dos momentos de cuatro horas. Así, la ingesta total de alimento no mostró diferencia $(\mathrm{p}>0,05)$ entre tratamientos, asumiendo que las vacas lograron mantener un consumo diario de MS constante ingiriendo, ya sea más pasto o ensilado de maíz. 
Cuadro 1. Contenido de minerales en los alimentos consumidos por vacas Holstein en pastoreo en el valle de Toluca, México. 20112012.

Table 1. Mineral content of foodstuffs consumed by grazing Holstein cows in the Toluca Valley, Mexico. 2011-2012.

\begin{tabular}{|c|c|c|c|c|c|c|c|}
\hline \multirow[b]{2}{*}{ Experimento $^{\dagger}$} & \multicolumn{3}{|c|}{1} & \multicolumn{3}{|c|}{2} & \multirow[b]{2}{*}{$\operatorname{Req}^{*}$} \\
\hline & Concentrado & Ensilado & Pasto & Concentrado & Ensilado & Pasto & \\
\hline Calcio, \% & 0,55 & 0,17 & 0,17 & 1,53 & 0,17 & 0,21 & 0,51 \\
\hline Fósforo, \% & 0,42 & 0,17 & 0,15 & 0,45 & 0,13 & 0,21 & 0,33 \\
\hline Relación Ca:P & 1,28 & 1,02 & 1,15 & 3,37 & 1,29 & 1,03 & $2: 1$ \\
\hline Magnesio, \% & 0,18 & 0,11 & 0,08 & 0,19 & 0,09 & 0,14 & 0,20 \\
\hline Potasio, \% & 0,49 & 0,66 & 0,64 & 0,67 & 0,71 & 1,14 & 0,90 \\
\hline Sodio, \% & 0,36 & 0,16 & 0,25 & 0,48 & 0,23 & 0,55 & 0,18 \\
\hline Cobre, ppm & 12 & $\mathrm{nd}^{\dagger}$ & nd & 18 & 9 & 16 & 10,0 \\
\hline Hierro, ppm & 164 & 111 & 151 & 157 & 176 & 110 & 50,0 \\
\hline Zinc, ppm & 128 & 18 & 15 & 22 & 10 & 10 & 40,0 \\
\hline
\end{tabular}

${ }^{\dagger}$ Experimento 1: vacas en pastoreo complementadas con distintos niveles de alimento concentrado. Experimento 2: vacas con distintos tiempos de permanencia en la pradera $/{ }^{\dagger}$ Experiment 1: grazing dairy cows supplemented with different levels of concentrated feed. Experiment 2: cows with different times of permanence in the prairie.

${ }^{*}$ Requerimientos de minerales para vacas lecheras (National Research Council, 2001), ${ }^{\dagger}$ nd: no determinado / Mineral requirements for dairy cows (National Research Council, 2001). ${ }^{\dagger}$ nd: undeterminate.

Cuadro 2. Ingestión diaria de alimento ( $\mathrm{kg}$ MS) y producción de leche ( $\left.\mathrm{kg} \mathrm{día}^{-1}\right)$ de vacas Holstein alimentadas con distintos niveles de concentrado (experimento uno) y diferentes tiempos de permanencia en la pradera (experimento dos) en el valle Toluca, México. 2011-2012.

Table 2. Daily feed intake (kg MS) and milk production ( $\left.\mathrm{kg} \mathrm{día}^{-1}\right)$ of Holstein cows fed with different concentrate levels (Exp. one) and different grazing time in the meadow (Exp. two) in the Toluca Valley, Mexico. 2011-2012.

\begin{tabular}{|c|c|c|c|c|c|}
\hline & Ensilado de maíz & Concentrado & Pasto & Consumo total & Producción de leche \\
\hline \multicolumn{6}{|l|}{$\operatorname{Exp} 1^{\dagger}$} \\
\hline $8 c$ & $8,13^{\text {a }}$ & $7,20^{\text {a }}$ & $1,14^{\mathrm{c}}$ & $16,48^{a}$ & $19,7^{\mathrm{a}}$ \\
\hline $5 c$ & $7,51^{\mathrm{b}}$ & $4,50^{\mathrm{b}}$ & $2,58^{\mathrm{b}}$ & $14,59^{\mathrm{b}}$ & $15,3^{\mathrm{b}}$ \\
\hline $3 c$ & 7,81 ab & $2,70^{\mathrm{c}}$ & $5,25^{\text {a }}$ & $15,76^{\mathrm{a}}$ & $16,2^{\mathrm{ab}}$ \\
\hline EEM $^{2}$ & 0,143 & 5,462 & 0,268 & 0,280 & 1,081 \\
\hline $\mathbf{p} \leq$ & 0,0344 & 0,0001 & 0,0001 & 0,0001 & 0,0304 \\
\hline \multicolumn{6}{|l|}{$\operatorname{Exp} 2$} \\
\hline $8 \mathrm{~h}$ & $10,11^{x}$ & 4,48 & $2,64^{y}$ & 17,24 & 21,48 \\
\hline $4+4 h$ & $8,94^{x}$ & 4,48 & $3,70^{y}$ & 17,13 & 21,96 \\
\hline $12 \mathrm{~h}$ & $6,44^{y}$ & 4,48 & $6,58^{x}$ & 17,50 & 21,86 \\
\hline EEM $^{2}$ & 0,320 & - & 0,315 & 0,149 & 0,216 \\
\hline $\mathbf{p} \leq$ & 0,0005 & - & 0,0003 & 0,2677 & 0,2632 \\
\hline
\end{tabular}

abc; $x y$ Valores medios en la misma columna en cada estrato con distinta literal son diferentes $(\mathrm{p}<0,05) /$ abc; $x y$ Mean values in the same column in each stratum with different literal are different $(\mathrm{p}<0.05)$.

† Tratamientos. Experimento 1: 8c: 7,2 kg de concentrado más acceso a la pradera de 07:00 a 15:00 h; 5c: 4,5 kg de concentrado más acceso a la pradera de 07:00 a 15:00 h y de 16:00 a 20:00 h; 3c: $2,7 \mathrm{~kg}$ de concentrado más acceso a la pradera de 07:00 a 15:00 h y de 16:00 a 20:00 h. Experimento 2: 8h: ocho horas de acceso a la pradera de 07:00 a 15:00 h; 4+4h: dos momentos de cuatro horas de acceso a la pradera, de 07:00 a 11:00 h y de 16:00 a 20:00 h; 12h: $12 \mathrm{~h}$ de acceso a la pradera, de 07:00 a 15:00h y 16:00 a 20:00 h/ ${ }^{\dagger}$ Treatments. Experiment 1: 8c: 7,2 kg concentrate plus pasture access from 07:00 to 15:00 h; 5c: 4,5 kg concentrate plus pasture access from $07: 00$ to $15: 00 \mathrm{~h}$ and 16:00 to $20: 00 \mathrm{~h} ; 3 \mathrm{c}: 2,7 \mathrm{~kg}$ concentrate plus pasture access from 07:00 to 15:00 $\mathrm{h}$ and 16:00 to 20:00 $\mathrm{h}$. Experiment 2: 8h: eight hours of pasture access from 07:00 to 15:00 h; 4+4h: two moments of four hours of pasture access from 07:00 to $15: 00 \mathrm{~h}$ and $16: 00$ to $20: 00 \mathrm{~h} ; 12 \mathrm{~h}$ : twelve hours of pasture access from 07:00 to 15:00h and 16:00 to 20:00 h.

${ }^{2}$ EEM: error estándar de la media / ${ }^{2}$ EEM: standard error of the mean. 


\section{Consumo de minerales}

El consumo total de minerales aquí reportado provino de sumar el resultado de multiplicar el contenido mineral de cada uno de los alimentos (forraje, ensilado de maíz y concentrado) por su respectivo consumo diario de MS. El consumo total de cada mineral fue dividido entre el consumo total de MS total y el resultado fue contrastado con los requerimientos diarios de minerales (por kg de MS) para bovinos lecheros (National Research Council, 2001) (Cuadro 2).

El consumo de minerales de los bovinos lecheros es mostrado en el Cuadro 3. A excepción de $\mathrm{K}$ y Fe, el consumo del resto de los minerales mostró diferencias $(\mathrm{p}<0,05)$ entre tratamientos en el experimento $1 ; \mathrm{y}$ en el caso del experimento 2 , el tiempo de permanencia en la pradera afectó $(\mathrm{p}<0,05)$ el consumo de Zn y de la mayoría de los macrominerales, a excepción del Ca.

Cuadro 3. Consumo diario de minerales $\left(\mathrm{g} \mathrm{día}^{-1}\right)$ de vacas Holstein alimentadas con distintos niveles de alimento concentrado (experimento uno) y diferentes tiempos de permanencia en la pradera (experimento dos) en el valle de Toluca, México. 2011-2012.

Table 3. Daily mineral consumption ( $\mathrm{g}$ día $^{-1}$ ) of Holstein cows fed with different concentrate feed levels (exp. 1) and different grazing times in the meadow (exp. 2) in the Toluca Valley, Mexico. 2011-2012.

\begin{tabular}{|c|c|c|c|c|c|c|c|c|}
\hline & $\mathrm{Ca}$ & $\mathbf{P}$ & Mg & $\mathbf{K}$ & $\mathbf{N a}$ & $\mathrm{Cu}$ & $\mathbf{F e}$ & Zn \\
\hline \multicolumn{9}{|l|}{ Exp. $1^{\dagger}$} \\
\hline $8 c$ & $55,33^{\mathrm{a}}$ & $46,03^{\mathrm{a}}$ & $23,47^{\mathrm{a}}$ & 95,97 & $41,55^{\mathrm{a}}$ & - & 2,28 & $1,08^{\mathrm{a}}$ \\
\hline $5 c$ & $41,43^{\mathrm{b}}$ & $35,19^{\mathrm{b}}$ & $18,68^{\mathrm{b}}$ & 85,85 & $33,45^{\mathrm{b}}$ & - & 1,93 & $0,75^{\mathrm{b}}$ \\
\hline $3 c$ & $36,16^{\mathrm{c}}$ & $31,6^{\mathrm{c}}$ & $17,52^{\mathrm{b}}$ & 95,04 & $33,60^{\mathrm{b}}$ & - & 2,16 & $0,55^{\mathrm{c}}$ \\
\hline EEM $^{2}$ & 0,966 & 0,855 & 0,445 & 3,716 & 1,485 & & 0,122 & 0,008 \\
\hline $\mathbf{p}<$ & $<0,00011$ & $<0,00011$ & $<0,00011$ & 0,1405 & 0,0022 & & 0,1444 & $<0,00011$ \\
\hline \multicolumn{9}{|l|}{ Exp. $2^{\dagger}$} \\
\hline $8 h$ & 90,47 & $38,75^{y}$ & $21,60^{y}$ & $131,93^{\mathrm{b}}$ & $59,54^{y}$ & $0,217^{y}$ & 2,74 & 0,227 \\
\hline $4+4 h$ & 90,39 & $39,29^{y}$ & $21,92^{y}$ & $137,51^{\mathrm{b}}$ & $64,20^{y}$ & $0,229^{y}$ & 2,70 & 0,223 \\
\hline $12 \mathrm{~h}$ & 92,64 & $41,23^{x}$ & $23,53^{x}$ & $151,48^{\mathrm{a}}$ & $75,26^{x}$ & $0,255^{x}$ & 2,61 & 0,226 \\
\hline $\mathbf{E E M}^{2}$ & 0,651 & 0,365 & 0,336 & 2,381 & 1,607 & 0,004 & 0,046 & 0,003 \\
\hline $\mathbf{p}<$ & 0,0846 & 0,0068 & 0,0139 & 0,0030 & 0,0012 & 0,0024 & 0,1819 & 0,696 \\
\hline
\end{tabular}

abc; xy Valores medios en la misma columna en cada estrato con distinta literal son diferentes $(\mathrm{p}<0,05) /$ abc; $x y$ Mean values in the same column in each stratum with different literal are different $(\mathrm{p}<0.05)$.

† Tratamientos. Experimento 1: 8c: 7,2 kg de concentrado más acceso a la pradera de 07:00 a 15:00 h; 5c: 4,5 kg de concentrado más acceso a la pradera de 07:00 a 15:00 h y de 16:00 a 20:00 h; 3c: 2,7 kg de concentrado más acceso a la pradera de 07:00 a 15:00 h y de 16:00 a 20:00 h. Experimento 2: 8h: ocho horas de acceso a la pradera de 07:00 a 15:00 h; 4+4h: dos momentos de 4 h de acceso a la pradera, de 07:00 a 11:00 h y de 16:00 a 20:00 h; 12h: $12 \mathrm{~h}$ de acceso a la pradera, de 07:00 a 15:00 h y 16:00 a 20:00h / ${ }^{\dagger}$ Treatments. Experiment 1: 8c: 7,2 kg concentrate plus pasture access from 07:00 to 15:00 h; 5c: 4,5 kg concentrate plus pasture access from 07:00 to $15: 00 \mathrm{~h}$ and $16: 00$ to $20: 00 \mathrm{~h} ; 3 \mathrm{c}: 2,7 \mathrm{~kg}$ concentrate plus pasture access from 07:00 to 15:00 $\mathrm{h}$ and 16:00 to 20:00 h. Experiment 2: 8h: eight hours of pasture access from 07:00 to 15:00 h; 4+4h: two moments of four hours of pasture access from 07:00 to 15:00h and 16:00 to 20:00 h; 12h: twelve hours of pasture access from 07:00 to 15:00 $\mathrm{h}$ and 16:00 to 20:00 $\mathrm{h}$.

${ }^{2}$ EEM: error estándar de la media / ${ }^{2}$ EEM: standard error of the mean.

El consumo de Ca bajó conforme el nivel de concentrado suministrado disminuyó, así, resultó insuficiente el consumo de este mineral $(0,28 \%)$ para cumplir el requerimiento $(0,51 \%$ BS) de vacas en producción (National Research Council, 2001). Contrariamente, aunque no significativo ( $p>0,05)$, el consumo de Ca $\left(91,16 \pm 12,66 \mathrm{~g} \mathrm{dí}^{-1}\right)$ 
representó el 0,53\% de la ingesta total por kg de MS, indistintamente del tiempo de permanencia de las vacas en la pradera.

El consumo de P fue $30 \%$ y $45 \%$ más alto $(\mathrm{p}<0,05)$ en el tratamiento $8 \mathrm{c}$ en comparación con $5 \mathrm{c}$ y $3 \mathrm{c}$, respectivamente; mientras que en el experimento 2, el consumo de $\mathrm{P}$ observado en los tratamientos $4+4 \mathrm{~h}$ y $8 \mathrm{~h}$ $\left(39,29\right.$ y $38,75 \mathrm{~g} \mathrm{día}^{-1}$, respectivamente) fue estadísticamente igual entre ellos, pero inferior $(\mathrm{p}<0,05)$ al observado en el tratamiento $12 \mathrm{~h}\left(41,23 \mathrm{~g} \mathrm{día}^{-1}\right)$. Así, el requerimiento de P $(0,33 \%$; National Research Council, 2001), no fue cubierto por los tratamientos evaluados, cuyo aporte de P varió de 0,22 a 0,24 \% en ambos experimentos.

El consumo de Mg mostró diferencias $(\mathrm{p}<0,05)$ entre tratamientos en ambos experimentos. En el tratamiento $8 \mathrm{c}$ el consumo fue $26,9 \%$ mayor comparado con los tratamientos 5 c y 3c. Por otro lado, el tratamiento $12 \mathrm{~h}$ registró el mayor consumo de $\mathrm{Mg}$ comparado con los tratamientos $8 \mathrm{~h}$ y $4+4 \mathrm{~h}$, los cuales mostraron consumos similares ( $>0,05)$. El nivel óptimo de Mg en la dieta para vacas en producción fue 0,18 \% (National Research Council, 2001), mismo que no fue cubierto en ninguno de los tratamientos, cuyo aporte fue de alrededor de $0,13 \%$.

El consumo de $\mathrm{K}$ resulto estadísticamente igual $(\mathrm{p}>0,05)$ entre tratamientos sin efecto por el nivel de concentrado suministrado $\left(92,29 \pm 9,10 \mathrm{~g} \mathrm{día}^{-1}\right)$, su aporte en la dieta fue de $0,6 \%$, valor que está por debajo del 0,9-1,0 \% requerido (National Research Council, 2001). En el experimento 2, aunque el tratamiento $12 \mathrm{~h}$ tuvo el mayor $(\mathrm{p}<0,05)$ consumo de $\mathrm{K}(0,87 \%)$ comparado con los grupos $8 \mathrm{~h}(0,77 \%)$ y 4+4h $(0,80 \%)$, en ningún caso se cubrió el requerimiento de $\mathrm{K}$ para vacas en producción.

El consumo de $\mathrm{Na}$ difirió entre tratamientos $(\mathrm{p}<0,05)$, el tratamiento $8 \mathrm{c}$ presentó el mayor consumo en comparación con $5 \mathrm{c}$ y $3 \mathrm{c}$ que fueron estadísticamente iguales. En el experimento 2, el tratamiento 12 h registró el mayor $(\mathrm{p}<0,05)$ consumo de $\mathrm{Na}\left(75,26 \mathrm{~g} \mathrm{día}^{-1}\right)$, con respecto a los tratamientos $8 \mathrm{~h}$ y $4+4 \mathrm{~h}$ los cuales no mostraron diferencias $(p>0,05)$ entre sí. El requerimiento mínimo de $\mathrm{Na}$ en dietas para vacas lecheras es de $0,22 \%$ (National Research Council, 2001), el cual fue cubierto en todos los tratamientos al observarse un consumo de Na de $0,25 \%$, $0,22 \%$ y $0,23 \%$ para $8 \mathrm{c}, 5 \mathrm{c}$ y $3 \mathrm{c}$, respectivamente; y entre 0,35 y $0,43 \%$ para los tratamientos con distinto tiempo de permanencia en la pradera.

El consumo de $\mathrm{Cu}$ fue mayor $(\mathrm{p}<0,05)$ en el tratamiento de 12 horas comparado con los tratamientos con menor tiempo de permanencia en la pradera, el aporte de $\mathrm{Cu}$ a las vacas cubrió su requerimiento. No hubo diferencias ( $p>0,05)$ en el consumo de Fe en los tratamientos de los experimentos $1\left(2,128 \pm 0,299\right.$ g día $\left.{ }^{-1}\right)$ y $2\left(2,687 \pm 0,495\right.$ g día ${ }^{-}$ ${ }^{1}$ ). El requerimiento de Fe es de $50 \mathrm{ppm}$ (National Research Council, 2001), mismo que fue cubierto en todos los casos, y fue rebasado en promedio en $2,7(135,9 \mathrm{ppm})$ y $3,1(155,2 \mathrm{ppm})$ veces para el experimento 1 y 2 , respectivamente.

Diferencias entre tratamientos $(\mathrm{p}<0,05)$ por efecto del nivel de concentrado suministrado se observaron en el consumo de $\mathrm{Zn}$, siendo mayor con el nivel de alimento concentrado más alto. En el experimento 2 no hubo diferencia $(\mathrm{p}>0,05)$ por efecto del tiempo de permanencia en la pradera; sin embargo, el consumo de $\mathrm{Zn}(13 \mathrm{ppm})$ fue menor al requerido (40 ppm) por vacas lecheras en lactación (National Research Council, 2001), indicando un aporte deficiente de $\mathrm{Zn}$ en la dieta.

\section{Minerales en suero sanguíneo}

El contenido de minerales en suero sanguíneo de bovinos productores de leche en pastoreo complementado con diferentes niveles de concentrado y tiempos de permanencia en la pradera se observa en el Cuadro 4 .

No se observaron diferencias $(\mathrm{p}>0,05)$ entre los tratamientos en la mayoría de los minerales en el suero sanguíneo de vacas en ambos experimentos, a excepción del contenido de $\mathrm{Mg}$ en el experimento dos y de $\mathrm{Cu}$ en el experimento uno (Cuadro 4).

Con respecto al contenido de microminerales, el $\mathrm{Cu}$ en suero sanguíneo fue el único mineral que mostró diferencias $(\mathrm{p}<0,05)$ entre tratamientos en el experimento 1 , siendo mayor en el tratamiento $8 \mathrm{c}$ y estadísticamente igual al tratamiento $5 \mathrm{c}$, pero diferente de $3 \mathrm{c}$, este último mostró el contenido más bajo de $\mathrm{Cu}$ en suero sanguíneo. 
Cuadro 4. Concentración de minerales en suero sanguíneo de vacas Holstein alimentadas con distinto nivel de concentrado (experimento 1) y diferentes tiempos de permanencia en la pradera (experimento 2) en el valle Toluca, México. 2011-2012.

Table 4. Mineral concentration in blood serum of Holstein cows fed with different concentrate levels (Experiment 1) and different grazing time in the meadow (Experiment 2) in the Toluca Valley, Mexico. 2011-2012.

\begin{tabular}{|c|c|c|c|c|c|c|c|c|}
\hline & \multicolumn{5}{|c|}{$\mathrm{mg} \mathrm{dl}^{-1}$} & \multicolumn{3}{|c|}{$\mathbf{m c g ~ m l ^ { - 1 }}$} \\
\hline & $\mathrm{Ca}$ & $\mathbf{P}$ & Mg & K & $\mathrm{Na}$ & $\mathrm{Cu}$ & $\mathrm{Fe}$ & $\mathbf{Z n}$ \\
\hline \multicolumn{9}{|l|}{$\operatorname{Exp} 1^{\dagger}$} \\
\hline $8 c$ & 6,97 & 8,47 & 1,41 & 20,41 & 320 & $0,88^{a}$ & 1,52 & 0,23 \\
\hline $5 c$ & 7,48 & 8,72 & 1,53 & 20,78 & 345 & $0,84^{\mathrm{ab}}$ & 1,47 & 0,34 \\
\hline $3 c$ & 7,21 & 7,94 & 1,35 & 20,78 & 337 & $0,66^{\mathrm{b}}$ & 1,50 & 0,37 \\
\hline EEM $^{2}$ & 0,285 & 0,331 & 0,076 & 0,646 & 9,814 & 0,059 & 0,083 & 0,062 \\
\hline $\mathbf{p}<$ & 0,4689 & 0,2719 & 0,2660 & 0,8956 & 0,2127 & 0,0438 & 0,9283 & 0,2518 \\
\hline$\% \mathrm{D}^{*}$ & 94,0 & 0,0 & 94,0 & 0,0 & 16,7 & 56,0 & 11,0 & 100 \\
\hline \multicolumn{9}{|l|}{ Exp $2^{\dagger}$} \\
\hline $8 \mathrm{~h}$ & 7,96 & 5,91 & $1,63^{x}$ & 23,77 & 374 & 0,86 & 1,54 & 0,37 \\
\hline $4+4 h$ & 8,01 & 6,21 & $1,53^{x y}$ & 23,77 & 378 & 0,70 & 1,39 & 0,37 \\
\hline $12 \mathrm{~h}$ & 7,62 & 6,07 & $1,40^{y}$ & 23,02 & 362 & 0,85 & 1,52 & 0,31 \\
\hline EEM $^{2}$ & 0,271 & 0,189 & 0,036 & 0,393 & 5,654 & 0,065 & 0,182 & 0,064 \\
\hline $\mathbf{p}<$ & 0,5797 & 0,5669 & 0,0136 & 0,3644 & 0,1882 & 0,2195 & 0,8283 & 0,7029 \\
\hline$\% \mathrm{D}^{\ddagger}$ & 58,3 & 0,0 & 100 & 0,0 & 0,0 & 63,8 & 38,9 & 97,2 \\
\hline $\mathbf{N C}^{\S}$ & 8,0 & 4,0 & 1,80 & 15,2 & 334 & 0,8 & 1,3 & 0,7 \\
\hline
\end{tabular}

abc Valores medios en la misma columna en cada estrato con distinta literal son diferentes $(p<0,05) /$ abc; $x y$ Mean values in the same column with different in each stratum with different literal are different $(\mathrm{p}<0.05)$.

† Tratamientos. Experimento 1: 8c: 7,2 kg de concentrado más acceso a la pradera de 07:00 a 15:00 h; $5 \mathrm{c}: 4,5 \mathrm{~kg}$ de concentrado más acceso a la pradera de 07:00 a 15:00 h y de 16:00 a 20:00 h; 3c: 2,7 kg de concentrado más acceso a la pradera de 07:00 a 15:00 h y de 16:00 a 20:00 h. Experimento 2: $8 \mathrm{~h}: 8 \mathrm{~h}$ de acceso a la pradera de 07:00 a 15:00h; 4+4h: dos momentos de $4 \mathrm{~h}$ de acceso a la pradera, de 07:00 a 11:00 h y de 16:00 a 20:00 h; 12h: $12 \mathrm{~h}$ de acceso a la pradera, de 07:00 a 15:00h y 16:00 a 20:00 h/ Treatments. Experiment 1: $8 \mathrm{c}: 7,2 \mathrm{~kg}$ concentrate plus pasture access from 07:00 to 15:00 h; 5c: 4,5 kg concentrate plus pasture access from 07:00 to 15:00 h and 16:00 to 20:00 h; $3 \mathrm{c}: 2,7 \mathrm{~kg}$ concentrate plus pasture access from 07:00 to 15:00 h and 16:00 to 20:00 h. Experiment 2: 8h: eight hours of pasture Access from 07:00 to 15:00h; 4+4h: two moments of four hours of pasture access from 07:00 to 15:00h and 16:00 to 20:00 h; 12h: twelve hours of pasture access from 07:00 to 15:00 $\mathrm{h}$ and 16:00 to 20:00 $\mathrm{h}$.

Porcentaje de muestras por debajo del nivel crítico / $\$$ Percent of samples below the critical level.

${ }^{2}$ EEM: error estándar de la media / ${ }^{2}$ EEM: standard error of the mean.

${ }^{\S}$ Nivel crítico (National Research Council, 2001) / ${ }^{\S}$ Critical level (National Research Council, 2001).

Por efecto del tiempo de permanencia en la pradera, el Mg en suero sanguíneo fue 6,5 y 16,5\% mayor $(\mathrm{p}<0,05)$ en el tratamiento $8 \mathrm{~h}$ comparado con los tratamientos $4+4 \mathrm{~h}$ y $12 \mathrm{~h}$, respectivamente. El tratamiento $12 \mathrm{~h}$ mostró el nivel más bajo de $\mathrm{Mg}$ (1,40 $\left.\mathrm{mg} \mathrm{dl}^{-1}\right)$, no obstante que los bovinos, en este tratamiento, mostraron mayor consumo de este mineral (23,53 $\left.\mathrm{g} \mathrm{día}^{-1}\right)$, aunque no fue suficiente para cubrir los requerimientos de $\mathrm{Mg}$ de los bovinos lecheros (National Research Council, 2001).

El tiempo de permanencia de las vacas en la pradera no afectó $(p>0,05)$ la concentración de los microminerales $\mathrm{Cu}\left(0,81 \pm 0,18 \mathrm{mcg} \mathrm{ml}^{-1}\right), \mathrm{Fe}\left(1,49 \pm 0,46 \mathrm{mcg} \mathrm{ml}^{-1}\right)$ y $\mathrm{Zn}\left(0,36 \pm 0,17 \mathrm{mcg} \mathrm{ml}^{-1}\right)$ en suero sanguíneo.

El Zn en suero sanguíneo de bovinos se encontró prácticamente en todas las muestras, por debajo del nivel crítico (0,7 y 1,3 $\mathrm{mcg} \mathrm{ml}^{-1}$; National Research Council, 2001) en ambos experimentos (Cuadro 4). 


\section{Correlaciones}

Los coeficientes de correlación entre las variables de consumo de minerales, producción de leche y contenido mineral en suero sanguíneo de bovinos complementados con distinto nivel de alimento concentrado (experimento uno) y con diferente tiempo de permanencia en la pradera (experimento dos) se indican en el Cuadro 5.

Cuadro 5. Coeficientes de correlación ( $\mathrm{r}$ ) entre el consumo de minerales, producción de leche y el contenido de minerales en suero sanguíneo de vacas Holstein alimentadas con distintos niveles de concentrado y distinto tiempo de permanencia en la pradera en el valle de Toluca, México. 2011-2012.

Table 5. Correlation coefficients (r) among mineral consumption, milk production, and mineral content in blood serum of Holstein cows fed with different concentrate levels and different grazing time in the meadow in the Toluca Valley, Mexico. 2011-2012.

\begin{tabular}{|c|c|c|c|c|c|c|c|c|}
\hline & $\mathbf{C a}$ & $\mathbf{P}$ & Mg & $\mathbf{K}$ & $\mathbf{N a}$ & $\mathbf{C u}$ & $\mathbf{F e}$ & $\mathbf{Z n}$ \\
\hline \multicolumn{9}{|c|}{ Experimento $1^{\dagger}$} \\
\hline \multicolumn{9}{|c|}{ Consumo de minerales-contenido en suero sanguíneo } \\
\hline $\mathrm{r}$ & $-0,053$ & 0,114 & 0,102 & $-0,267$ & $-0,651$ & $-0,200$ & $-0,014$ & $-0,306$ \\
\hline $\mathrm{p}=$ & 0,833 & 0,581 & 0,687 & 0,284 & 0,003 & 0,426 & 0,955 & 0,217 \\
\hline \multicolumn{9}{|c|}{ Consumo de minerales-producción de leche } \\
\hline $\mathrm{r}$ & 0,622 & 0,653 & 0,614 & 0,429 & 0,523 & 0,067 & 0,675 & 0,563 \\
\hline $\mathrm{p}=$ & 0,006 & 0,003 & 0,007 & 0,075 & 0,026 & 0,798 & 0,002 & 0,015 \\
\hline \multicolumn{9}{|c|}{ Contenido en suero sanguíneo-producción de leche } \\
\hline $\mathrm{r}$ & 0,112 & 0,131 & 0,217 & 0,252 & $-0,462$ & 0,162 & $-0,163$ & $-0,077$ \\
\hline $\mathrm{p}=$ & 0,657 & 0,604 & 0,387 & 0,313 & 0,054 & 0,521 & 0,517 & 0,760 \\
\hline \multicolumn{9}{|c|}{ Experimento $2^{\dagger}$} \\
\hline \multicolumn{9}{|c|}{ Consumo de minerales-contenido en suero sanguíneo } \\
\hline $\mathrm{r}$ & 0,212 & $-0,155$ & $-0,551$ & 0,440 & 0,007 & $-0,258$ & $-0,272$ & 0,271 \\
\hline $\mathrm{p}=$ & 0,397 & 0,540 & 0,017 & 0,067 & 0,977 & 0,300 & 0,274 & 0,276 \\
\hline \multicolumn{9}{|c|}{ Consumo de minerales-producción de leche } \\
\hline $\mathrm{r}$ & 0,256 & 0,836 & 0,553 & 0,731 & 0,598 & 0,567 & 0,555 & 0,629 \\
\hline $\mathrm{p}=$ & 0,305 & $<0,001$ & 0,017 & $<0,001$ & 0,008 & 0,014 & 0,016 & 0,005 \\
\hline \multicolumn{9}{|c|}{ Contenido en suero sanguíneo-producción de leche } \\
\hline $\mathrm{r}$ & $-0,257$ & $-0,140$ & $-0,457$ & 0,425 & 0,234 & $-0,243$ & $-0,329$ & 0,199 \\
\hline $\mathrm{p}=$ & 0,303 & 0,578 & 0,056 & 0,078 & 0,349 & 0,331 & 0,182 & 0,426 \\
\hline
\end{tabular}

${ }^{\dagger}$ Experimento 1: vacas en pastoreo complementadas con distintos niveles de concentrado. Experimento 2: vacas con distintos tiempos de permanencia en la pradera $/{ }^{\dagger}$ Experiment 1 : grazing dairy cows supplemented with different levels of concentrate. Experiment 2 : cows with different times of permanence in the prairie.

El consumo de la mayoría de macro y micro minerales por los bovinos productores de leche en pastoreo en ambos experimentos, no mostró relación $(\mathrm{p}>0,05)$ con el contenido en suero sanguíneo (Cuadro 5). Solamente fue observada una correlación negativa media $(\mathrm{r}=-0,65, \mathrm{p}=0,003)$ entre el consumo de $\mathrm{Na}$ y su contenido en suero sanguíneo de vacas complementadas con distinto nivel de concentrado; mientras que en vacas con distinto tiempo 
de permanencia en la pradera, se observó una correlación negativa $(r=-0,55, p=0,01)$ entre el consumo de $\mathrm{Mg}$ y su contenido en suero sanguíneo.

La producción de leche de vacas en pastoreo complementadas con diferente nivel de alimento concentrado estuvo correlacionada positivamente ( $\mathrm{p}<0,05)$ con el consumo de $\mathrm{Ca}, \mathrm{P}, \mathrm{Mg}, \mathrm{Na}, \mathrm{Fe}$ y $\mathrm{Zn}$ (Cuadro 5), mientras que para las vacas con distinto tiempo de permanencia en la pradera ambas variables se correlacionaron positivamente $(\mathrm{p}<0,05)$ para la gran mayoría de los minerales analizados, excepto $\mathrm{Ca}(\mathrm{r}=0,25 ; \mathrm{P}=0,30)$.

Los microminerales $\mathrm{Cu}, \mathrm{Fe}$ y $\mathrm{Zn}$ se correlacionaron positivamente $(\mathrm{p}<0,05)$ con la producción de leche en el experimento dos, menos $\mathrm{Cu}$ en el experimento 1 (Cuadro 5).

No hubo correlación $(p>0,05)$ entre el contenido de minerales en suero sanguíneo de vacas lecheras y su producción láctea en ambos experimentos (Cuadro 5). Solo tendencias podrían ser asumidas en la correlación negativa baja entre el contenido de $\mathrm{Na}$ en suero sanguíneo y la producción de leche $(\mathrm{r}=-0,46 ; \mathrm{p}=0,054)$, así, al reducir el nivel de concentrado en la dieta, la producción de leche disminuyó y el contenido de Na en el suero sanguíneo incrementó.

\section{Regresión}

La aplicación del análisis de regresión para predecir la concentración de minerales en suero sanguíneo a partir del consumo de minerales y la producción de leche solo fue significativa para el $\mathrm{P}\left(\mathrm{PSS}, \mathrm{mg} \mathrm{dl}^{-1} ; \mathrm{p}=0,005 ; \mathrm{R}^{2}=\right.$ $0,73)$ y $\mathrm{Mg}\left(\mathrm{MgSS}, \mathrm{mg} \mathrm{dl}^{-1} ; \mathrm{p}=0,003 ; \mathrm{R}^{2}=0,48\right)$ en suero sanguíneo en el experimento dos,

$$
\begin{gathered}
\text { PSS } \left.=11,11423-0,16959\left(\text { consumo de } \mathrm{P}, \mathrm{g} \text { día } \mathrm{a}^{-1}\right)+0,28940\left(\text { consumo de Mg, g día } \mathrm{a}^{-1}\right)\right] \\
\operatorname{MgSS}=0,96218+0,0941\left(\text { consumo de } \mathrm{P}, \mathrm{g} \text { día }{ }^{-1}\right)
\end{gathered}
$$

\section{Discusión}

El ganado lechero con un peso vivo (PV) promedio de $680 \mathrm{~kg}$, 90 días de lactación y una producción de $25 \mathrm{~kg}$ de leche por día requiere consumir 19,6 kg de MS, mientras que vacas de $450 \mathrm{~kg}$ de PV con producción de $20 \mathrm{~kg}$ de leche por día requieren consumir 16,5 kg de MS (National Research Council, 2001). En la presente investigación la producción láctea no superó los 20,0 $\mathrm{kg} \mathrm{día}^{-1}$ de leche en el caso de las vacas del experimento uno, por lo que se esperarían consumos de MS de alrededor de $16 \mathrm{~kg}$ (National Research Council, 2001); y en el segundo experimento tanto el consumo total de MS como la producción de leche fueron mayores en concordancia con lo indicado por el National Research Council (2001).

El consumo de minerales, se calcula desde el consumo total de materia seca y la concentración mineral en los alimentos (Cuadro 3). Los minerales se encuentran en plantas y alimentos en formas diversas, algunas de las cuales podría influir en la eficiencia en la cual son absorbidos y utilizados por el ganado (Suttle, 2010). Aun cuando no se cubrió el requerimiento de $\mathrm{P}$ en ambos experimentos, los rumiantes son capaces de movilizar reservas de este mineral para corregir la deficiencia (Mathews et al., 1998).

En relación al alto consumo de $\mathrm{Fe}$ en ambos experimentos, el National Research Council (2001), ha manifestado que la ingesta de este mineral por encima de 1000 ppm puede generar interferencia en la observación de minerales como $\mathrm{Cu}$ y $\mathrm{Zn}$.

El contenido de Ca en suero sanguíneo de los bovinos en ambos experimentos fue bajo en comparación con lo reportado en suero de vacas evaluadas en cuatro localidades del valle de Toluca, México en dos épocas del año (15,18-17,12 $\mathrm{mg} \mathrm{dl}^{-1}$; Morales-Almaraz et al., 2007), además, estuvo por debajo del nivel normal (9-10 $\left.\mathrm{mg} \mathrm{dl}^{-1}\right)$ (National Research Council, 2001). Cuando los niveles de Ca en la dieta son deficientes, los animales son capaces 
de movilizar las reservas presentes del hueso para mantener los niveles normales en sangre (National Research Council, 2005); no es común encontrar deficiencia de Ca en vacas en pastoreo pero en animales con altos estándares raciales los requerimientos de este mineral se incrementan y es posible observar deficiencia del mismo (McDowell \& Arthington, 2005; Suttle, 2010). Por ello, llama la atención que el $94 \%$ de las muestras de este estudio estuvieron por debajo del nivel crítico de $\mathrm{Ca}$ en suero en el experimento 1 y cerca del $60 \%$ en el experimento 2, aun cuando se cubrió el requerimiento de $\mathrm{Ca}$ de las vacas en este último.

Los niveles de P en suero sanguíneo de vacas lecheras estuvieron dentro de los rangos normales (4 a $\left.8 \mathrm{mg} \mathrm{dl}^{-1}\right)$ (National Research Council, 2001) en ambos experimentos, a pesar de haberse observado un defecto en la ingestión de este mineral y de que su aporte con la dieta fue insuficiente para cubrir las necesidades de las vacas lecheras (Cuadro 3). Por ejemplo, el tratamiento 8h mostró el menor consumo de P (38,75 g día $\left.{ }^{-1}\right)$ y su contenido en suero sanguíneo fue cuantitativamente la más baja (Cuadro 4). Otros autores Morales-Almaráz et al. (2007) reportaron valores similares a los encontrados en este trabajo $\left(6,88 \mathrm{mg} \mathrm{dl}^{-1}\right)$.

El nivel adecuado de $\mathrm{P}$ en suero sanguíneo se explicaría porque los rumiantes tuvieron la capacidad de reciclar este mineral (Mathews et al., 1998), sin embargo, la ingestión insuficiente de P se ha relacionado con la baja fertilidad, la aparente disfunción de los ovarios determina la inhibición, disminución e irregularidad de los celos, además, la deficiencia de este elemento puede reducir la producción de leche en las vacas (McDonald et al., 2001). Así, pese a no haberse observado concentraciones de P por debajo del nivel crítico en ninguno de los experimentos, deberá atenderse el aporte adecuado de $\mathrm{P}$ en la dieta, dado que a mediano o largo plazo podría verse afectado el desempeño reproductivo del animal.

El rango normal de $\mathrm{Mg}$ en suero sanguíneo es de 1,8 a 2,4 $\mathrm{mg} \mathrm{dl}^{-1}$, casi la totalidad de las vacas (94 y $100 \%$ en los experimentos 1 y 2, respectivamente) presentaron una concentración de $\mathrm{Mg}$ en suero sanguíneo por debajo del nivel crítico (McDowell et al., 1993; National Research Council, 2001).

La deficiencia de $\mathrm{Mg}$ en las vacas se pudo deber al consumo insuficiente de este mineral. La hipomagnesemia puede ser precedida por niveles de $\mathrm{Mg}$ en suero sanguíneo de $0,5 \mathrm{mg} \mathrm{dl}^{-1}$; el contenido de $\mathrm{Mg}$ en la orina es un mejor indicador de la deficiencia que el contenido en suero, ya que los niveles de este último no descienden hasta que existe una deficiencia grave (McDonald et al., 2001). Aunque la causa de hipomagnesemia no está bien determinada, el factor primario parece ser la absorción inadecuada de $\mathrm{Mg}$ en el tracto digestivo. En comparación con los resultados obtenidos, otros autores reportaron, en promedio, más del doble del contenido de $\mathrm{Mg}$ en suero sanguíneo de bovinos $\left(3,29 \mathrm{mg} \mathrm{dl}^{-1}\right)$ de diferentes localidades del valle de Toluca (Morales-Almaráz et al., 2007), particularmente, estos autores reportaron un contenido de 2,94 $\mathrm{mg} \mathrm{dl}^{-1} \mathrm{de} \mathrm{Mg}$ en suero sanguíneo de bovinos en la zona del Cerrillo Piedras Blancas, Toluca, misma zona donde se efectuaron ambos experimentos del presente estudio.

Un exceso de $\mathrm{K}$ asociado con un bajo contenido de $\mathrm{Na}$ en la dieta disminuye la absorción e incrementan la excreción de Mg en las heces (Chiy \& Phillips, 1996).

El contenido de Na de los alimentos (Cuadro 1) y el consumo de materia seca cubrió los requerimientos de $\mathrm{Na}$ en todos los tratamientos (Cuadro 3); sin embargo, el aporte de K de la dieta no cubrió las necesidades de los bovinos (National Research Council, 2001). Respecto a este último mineral, a pesar de no haberse cubierto los requerimientos en el ganado lechero, en ningún caso, bajo las estrategias de alimentación evaluadas, se observaron concentraciones de $\mathrm{K}$ en suero sanguíneo por debajo del nivel crítico.

Concentraciones de $\mathrm{Na}$ en suero sanguíneo de vacas en lactación superiores a las del presente estudio han sido reportadas por otros autores (Vite, 2002; Morales-Almaráz et al., 2007). Los niveles de Na en suero sanguíneo y la dieta tienen muy poca correlación para determinar una deficiencia, la prueba más confiable es la toma de muestra de saliva (McDowell, 1985).

Las deficiencias de $\mathrm{Na}$ en animales en pastoreo ocurre cuando el pasto es deficiente en ese mineral, el cual varía con la especie de la planta y la ápoca (Dryden, 2008). En los alimentos, se observó un contenido adecuado de Na, 
sin embargo, en el caso de las vacas en el experimento 1, independientemente del nivel de alimento concentrado ofertado, no se cubrió su requerimiento; no obstante, la concentración de $\mathrm{Na}$ en suero fue adecuada.

Los valores de $\mathrm{Cu}$ encontrados en suero de vacas fueron similares a los reportados en la misma zona de estudio $\left(0,76 \mathrm{mcg} \mathrm{ml}^{-1}\right)$ (Morales-Almaraz et al., 2007). El rango óptimo de Cu en suero sanguíneo es de 0,80 a 1,50 mcg $\mathrm{ml}^{-1}$ (Puls, 1994), nivel que no fue alcanzado en el tratamiento 3c. Más de la mitad de la muestras (56 \% y $64 \%$, respectivamente para el experimento 1 y 2) estuvieron por debajo del nivel crítico de $\mathrm{Cu}$ en suero sanguíneo de los bovinos. La absorción de $\mathrm{Cu}$ se vio afectada por el exceso de Mo en la dieta y niveles menores a $0,5 \mathrm{mcg} \mathrm{ml}^{-1}$ representarían definitivamente una deficiencia de este mineral (National Research Council, 2001).

La habilidad de un alimento para cubrir los requerimientos de $\mathrm{Cu}$ depende más de la absorción que de la concentración de $\mathrm{Cu}$ que contiene (Suttle, 2010). Por otro lado, ligeras deficiencias o excesos de nutrientes en animales son difíciles de identificar, porque sus efectos son con frecuencia similares a aquellos debidos a la desnutrición o la presencia de parásitos internos, y aunque los síntomas patológicos podrían ocurrir, estos con frecuencia no son específicos para cualquier elemento o nutriente (Whitehead, 2000).

Cuantitativamente, el nivel más bajo de $\mathrm{Cu}$ en suero fue para el tratamiento 4+4h, el cual se encontró por debajo del nivel crítico $\left(0,80 \mathrm{mcg} \mathrm{ml}^{-1}\right)$ (Puls, 1994), y no tuvo coincidencia con el adecuado consumo de $\mathrm{Cu}$ en la dieta, pero el alto consumo de Fe observado en este trabajo pudo interferir de manera negativa en la absorción y metabolismo del $\mathrm{Cu}$ (McDowell et al., 1993). Para observar deficiencias de $\mathrm{Cu}$ en plasma pueden pasar muchos meses, ya que el animal tiene la capacidad de mantener el nivel de $\mathrm{Cu}$ normal en suero al recurrir a las reservas contenidas en el hígado (Minson, 1990).

El contenido de Fe en suero sanguíneo, independientemente del nivel de alimento concentrado suministrado en la dieta y del tiempo de permanencia en la pradera, estuvo dentro de los niveles normales 1,3-2,5 $\mathrm{mcg} \mathrm{ml}^{-1}$ (Puls, 1994). No obstante, el 11 y $38 \%$ de las muestras del experimento 1 y 2 respectivamente, se ubicaron por debajo del nivel crítico. La deficiencia de Fe rara vez se presenta en animales adultos en pastoreo, entre otras cosas, por el consumo indirecto de Fe proveniente del suelo que contamina a los forrajes (McDowell \& Arthington, 2005). En situaciones específicas como la pérdida de sangre o como consecuencia de enfermedades parasitarias masivas que provoquen disturbios del metabolismo puede existir una deficiencia de Fe (McDowell, 1985; Suttle, 2010). Excesos de Co y Zn también interfieren con la absorción de Fe (Henry \& Miller, 1995).

Los niveles de $\mathrm{Zn}$ en suero sanguíneo son afectados cuando los animales son sometidos a estrés y por presencia de patologías; niveles de $0,4 \mathrm{mcg} \mathrm{ml}^{-1}$ en suero sanguíneo son un indicativo de deficiencia de Zn (Huerta, 1999; National Research Council, 2001), tal y como se observó en las vacas en ambos experimentos. Respecto a los resultados obtenidos, niveles de $\mathrm{Zn}$ deficientes, pero ligeramente superiores $\left(0,56 \mathrm{mcg} \mathrm{ml}^{-1}\right)$, fueron reportados en la misma zona (Morales-Almaraz et al., 2007). La deficiencia de Zn pudo deberse a que el animal ingirió poco Zn (deficiencia primaria), ya sea por el bajo contenido de $\mathrm{Zn}$ en la dieta o la poca disponibilidad de este elemento, o cuando existen antagonistas (deficiencia secundaria) generadas por el desbalance de componentes en la dieta (Huerta, 1999); los excesos de Ca, P y Cu inhiben la absorción de Zn (Kumaresan et al., 2010).

El consumo de minerales y su relación con los mismos en suero sanguíneo, no mostraron ser variables asociativas para la gran mayoría de los minerales evaluados en el presente estudio. La correlación negativa media de $\mathrm{Na}$ indicaría que el déficit en el consumo de Na resultó en el aumento del contenido de este mineral en el suero sanguíneo de las vacas suplementadas con distinto nivel de alimento concentrado.

La correlación negativa media de $\mathrm{Mg}$ en el experimento 2, indicaría que el bajo consumo de $\mathrm{Mg}$, lo cual repercutió en la insatisfacción de las necesidades de Mg para el animal, aumentó su concentración en el suero sanguíneo.

Una correlación negativa $(\mathrm{r}=-0,67)$ entre el contenido de $\mathrm{Mg}$ del pasto y la de $\mathrm{Mg}$ en suero sanguíneo de vacas lecheras, se observó en otro estudio de diagnóstico, no obstante, no se reportaron datos de consumo de minerales (Morales-Almaraz et al., 2007). Por el contrario, evaluando el estado mineral del suelo, de la planta y del animal 
en una zona subtropical en la India, se observó una correlación alta positiva de Mg entre el consumo de forraje y el suero sanguíneo de bovinos ( $\mathrm{r}=0,88 ; \mathrm{p}<0,05)$ (Kumaresan et al., 2010).

En el experimento 1, conforme se redujo el nivel de alimento concentrado en la dieta, disminuyó el consumo de minerales y también la producción de leche. Como se ha descrito con antelación, el consumo de algunos minerales en la dieta no alcanzó a cubrir los requerimientos de las vacas en lactación; varios autores afirman que la deficiencia de $\mathrm{Ca}, \mathrm{P}, \mathrm{Mg}$ y Na, muestran, entre otros efectos en común, la disminución de la producción de leche, lo cual apoya la aseveración que el consumo de minerales es de vital importancia para una adecuada productividad del animal (Huerta, 1999; McDowell et al., 1993; Suttle, 2010).

La relación positiva entre el consumo de $\mathrm{P}$ y la producción de leche en ambos experimentos (Cuadro 5), está bien establecida al referenciar que el $\mathrm{P}$ es un nutriente esencial utilizado para el desarrollo de los huesos, el crecimiento y la producción óptima del ganado (McDowell \& Arthington, 2005); el P influye directamente sobre la ganancia de peso corporal y la producción láctea (Church \& Pound, 1987). Similarmente, la correlación positiva $(\mathrm{r}=0,59 ; \mathrm{p}=0,008)$ del consumo de $\mathrm{Na}$ con la producción de leche fue indicativo del adecuado aporte y consumo de este elemento, dado que la deficiencia de $\mathrm{Na}$ se manifiesta por la reducción del consumo de alimento, la menor producción de leche y la pérdida de peso (McDowell et al., 1993; Suttle, 2010).

$\mathrm{El}$ menor consumo de $\mathrm{Cu}$ en el tratamiento de $8 \mathrm{~h}$ coincidió cuantitativamente con la producción de leche más baja en el experimento 2; el $\mathrm{Cu}$ es un elemento esencial para rumiantes, la cantidad de $\mathrm{Cu}$ en la dieta depende de la edad del animal, la forma química del mineral y la presencia de sustancias que interfieren en su absorción (National Research Council, 2001). La deficiencia de $\mathrm{Cu}$ se manifiesta, además de una reducción del crecimiento y pérdida de peso, en la disminución en la producción de leche (Suttle, 2010).

La relación positiva entre la producción de leche y el consumo de $\mathrm{Zn}$ fue más clara en el experimento 1, se observó menor consumo de Zn con la reducción del nivel de alimento concentrado, asociado a un menor rendimiento de leche. La lactación representa una demanda mayor de Zn a pesar de su bajo contenido en la leche (Miller, 1979). Cuando los rumiantes son alimentados con dietas deficientes en Zn, la utilización de la proteína es afectada y el consumo voluntario es deprimido, lo cual podría limitar la productividad del animal (Suttle, 2010).

El consumo de minerales en las vacas con distinto nivel de alimento concentrado no fue una variable capaz de apoyar la predicción del estado mineral de los bovinos.

El animal regula, para la mayoría de los minerales, su concentración en fluidos (suero sanguíneo) y su aprovechamiento (absorción y metabolismo) a partir de su aporte en la dieta y de sus reservas corporales, lo cual, asociado a otros factores como el nivel de producción, estado fisiológico y sanitario, entre otros, hacen difícil la interpretación tanto de los desbalances observados en el contenido mineral en suero sanguíneo como el efecto de la correlación entre las variables estudiadas, particularmente del consumo con el contenido mineral en suero sanguíneo.

\section{Conclusiones}

Las estrategias de alimentación evaluadas tuvieron influencia sobre el consumo de minerales de los bovinos lecheros en pastoreo. Los niveles de alimento concentrado evaluados en el experimento 1 no cubrieron los requerimientos de $\mathrm{Ca}, \mathrm{P}, \mathrm{Mg}$ y $\mathrm{K}$, y excedieron los de $\mathrm{Fe}$. El requerimiento de $\mathrm{Zn}$ solo fue cubierto al suministrar $5 \mathrm{u} 8 \mathrm{~kg}$ de alimento concentrado en la dieta. Los distintos tiempos de permanencia en la pradera no cubrieron el requerimiento de $\mathrm{P}, \mathrm{Mg}$ y $\mathrm{Zn}$; excedieron el de $\mathrm{K}$ y Fe, y solo cumplieron con las necesidades de $\mathrm{Ca}$, $\mathrm{Na}$ y $\mathrm{Cu}$.

Independientemente del nivel de alimento concentrado o el tiempo de permanencia en la pradera, el contenido mineral en suero sanguíneo de los bovinos fue normal para $\mathrm{P}, \mathrm{Na}, \mathrm{Cu}$ y Fe, crítica para Ca; deficiente en $\mathrm{Mg}$ y Zn, y excesiva en $\mathrm{K}$. 
El consumo mineral y la producción de leche mostraron estrecha correlación, así que conocer el aporte de minerales en la dieta y la medición del consumo de alimento, resultó en un mejor indicador del impacto de la nutrición mineral en la producción de leche.

Los desbalances observados en suero sanguíneo, particularmente de $\mathrm{Ca}, \mathrm{K}, \mathrm{Mg}$ y $\mathrm{Zn}$, indicarían que es necesario adecuar su complementación en la ración de los bovinos en la zona de estudio, con el objetivo de satisfacer las necesidades de estos en vacas lactantes bajo condiciones de pastoreo.

Bajo las condiciones en que fue realizada la presente investigación, el análisis del consumo de minerales, no parece ser un parámetro confiable para correlacionarlo con la concentración mineral en el suero sanguíneo para la mayoría de los minerales analizados como lo demostró la falta de efecto de la correlación entre estas variables. Además del estado mineral del animal y del aporte mineral de los alimentos, se requieren más estudios encaminados a medir el consumo de minerales y parámetros productivos y reproductivos, que contribuyan a mejorar el desempeño del animal cuando la utilización de forrajes frescos y conservados es la base de su alimentación.

\section{Referencias}

Allan, J. E. (1971). The preparation of agricultural samples for analysis by atomic absorption spectroscopy. Varian Techtron.

Arriaga-Jordán, C. M., Flores-Gallegos, F. J., Peña-Carmona, G., Albarrán-Portillo, B, García-Martínez, A., Espinoza-Ortega, A., González-Esquivel C. E., \& Castelán-Ortega, O. A. (2001). Participatory on-farm evaluation of the response to concentrate supplementation by cows in early lactation in smallholder peasant (campesino) dairy production systems in the highlands of central Mexico. Journal of Agricultural Science, 137, 97-103. https://doi.org/10.1017/ S0021859601001095

Castro-Hernández, H., Domínguez-Vara, I. A., Morales-Almaráz, E., \& Huerta-Bravo, M. (2017). Composición química, contenido mineral y digestibilidad in vitro de raigrás (Lolium perenne) según intervalo de corte y época de crecimiento. Revista Mexicana de Ciencias Pecuarias, 8(2), 201-210.

Chiy, P. C., \& Phillips, C. J. C. (1996). Sodium nutrition of dairy cows. In: C.J. C. Phillips (Ed.), Progress in dairy science (pp. 29-44). CAB International.

Church, D. C., \& Pound, W. G. (1987). Fundamentos de nutrición y alimentación de los animales. Limusa-Noriega.

Domínguez-Vara I. A., \& Huerta-Bravo, M. (2008). Concentración e interrelación mineral en suelo, forraje y suero de ovinos durante dos épocas, en el Valle de Toluca, México. Agrociencia, 42(2), 173-183. http://www.scielo.org.mx/pdf/agro/ $\mathrm{v} 42 \mathrm{n} 2 / \mathrm{v} 42 \mathrm{n} 2 \mathrm{a} 5 . \mathrm{pdf}$

Dryden, G. (2008). Animal Nutrition Science. CABI.

Fick, K. A., McDowell, L. R., Miles, P. H., Wilkinson, N. S., Funk, J. D. Conrad, J. H., \& Valdivia, R. (1979). Métodos de análisis de minerales para tejidos de plantas y animales. Universidad de Florida.

Fleming, G. A. (1973). Mineral composition of herbage chemistry and biochemistry (Vol. 1). Academic Press.

Harris, W. D., \& Popat, P. (1954). Determination of the phosphorus content of lipids. Journal of the American Oil Chemists' Society, 31(4),124-127. https://doi.org/10.1007/BF02545694

Henry, P. R., \& Miller, E. R. (1995). Iron bioavailability. In: C. B. Ammerman, D. H. Baker, \& A. J. Lewis (Eds.), Bioavailability of Nutrients for Animals (pp. 169-199). Academic Press. 
Herdt, T. H., \& Hoff, B. (2011). The use of blood Analysis to evaluate trace mineral status in ruminant livestock. Veterinary Clinics of North America Food Animal Practice, 27, 255-283. https://doi.org/10.1016/j.cvfa.2011.02.004

Huerta, B. M. (1999). Interaction of dietary zinc and growth implants on weight gain, carcass traits and zinc in tissues of beef cattle [Doctoral dissertation, Washington State University] ProQuest. https://search.proquest.com/ docview/304643156?pq-origsite=summon

Instituto Nacional de Estadística y Geografía. (2007). Marco geoestadístico 2007 (Censos Agropecuarios 2007). https://www. inegi.org.mx/app/biblioteca/ficha.html?upc=702825292867

Kincaid, R. L. 1999. Assessment of trace mineral status of ruminants: A review. Journal of Animal Science, 77(1), 1-8. https:// doi.org/10.2527/jas2000.77E-Suppl1x

Kumaresan, A., Bujarbaruah, K. M., Pathak, K. A., \& Brajendra Ramesh, T. (2010). Soil-plant animal continuum in relation to macro and micro mineral status of dairy cattle in subtropical hill agro ecosystem. Tropical Animal Health and Production, 42(4), 569-577. https://doi.org/10.1007/s11250-009-9459-8

Macoon, B., Sollenberger, L. E., Moore, J. E., Staples, C. R., Fike, J. K., \& Portier, K. M. (2003). Comparison of three techniques for estimating the forage intake of lactating dairy cows on pasture. Journal of Animal Science, 81(9), 2357-2366. https://doi.org/10.2527/2003.8192357x

Mathews, B., Tristchler II, J. P., \& Miyasaka, S. C. (1998). Phosphorous management and sustainability. In J. H. Cherney \& D. J. R. Cherney (Eds), Grass for dairy cattle (pp. 193-222). CAB International.

McDonald, P., Edwards, R. A., Greenhalg, J. F. P., \& Morgan, C. A. (2001). Animal Nutrition (6th ed). Prentice Hall.

McDowell, L. R., \& Arthington, J. D. (2005). Minerals for grazing ruminants in tropical regions (4th ed). Institute of Food and Agricultural Sciences, University of Florida.

McDowell, L. R., Conrad, J. H., Hembry, F. G., Rojas, L. X., \& Velásquez, J. (1993). Minerales para rumiantes en pastoreo en regiones tropicales (2. ${ }^{\mathrm{a}}$ ed.). Universidad de Florida.

McDowell, L. R. (1985). Nutrition of grazing ruminants in warm climates. Academic Press.

Meda-Alducin, P. (2017). Diagnóstico y suplementación mineral en vacas Holstein en la Comarca Lagunera, México (Tesis doctoral no publicada), Universidad Autónoma Chapingo.

Menke, K. H., \& Steingass, H. (1988). Estimation of energetic feed value obtained from chemical analysis and in vitro gas production using rumen fluid. Animal Resource Development, 28, 7-55.

Miller, W. J. (1979). Dairy cattle feeding and nutrition. Academic Press.

Minson, D. J. (1990). Forages in Ruminant Nutrition. Academic Press.

Morales-Almaraz, E., Domínguez-Vara, I. A., González-Ronquillo, M., Jaramillo-Escutia, G., Castelán-Ortega, O. A., PescadorSalas, N., \& Huerta-Bravo, M. (2007). Diagnóstico mineral en forraje y suero sanguíneo de bovinos lecheros en dos épocas en el valle central de México. Técnica Pecuaria en México, 45(3), 329-344.

National Research Council. (2001). The nutrient requirements of dairy cattle. National Academic Press.

National Research Council. (2005). Mineral Tolerance of Animals (2nd ed). National Academies Press.

Puls, R. (1994). Minerals Levels in Animal Health. Diagnostic Data (2nd ed). Sherpa International.

Suttle, N. F. (2010). Mineral nutrition of livestock (4th ed). CABI. 
Tergas, L. E., \& Blue, W. G. (1971). Nitrogen and Phosphorous in Jaraguagrass (Hyparrhenia rufa (Nees) Stapf) during the dry season in a tropical savanna as affected by nitrogen fertilization. Agronomy Journal, 63(1), 6-9. https://doi. org/10.2134/agronj1971.00021962006300010003x

Vite, A. A. (2002). Caracterización del Estado mineral en ganado lechero del rancho San Lorenzo, Huaquechula, Puebla (Tesis profesional no publicada). Universidad Autónoma Chapingo.

Wayne-Cook, C. (1964). Symposium on nutrition of forages and pastures: Collecting samples for representative of ingested material of grazing animals for nutritional studies. Journal of Animal Science, 23(1), 265-270. https://doi.org/10.2527/ jas1964.231265x

Whitehead, C. D. (2000). Nutrient Elements in Grassland. Soil-Plant-Animal Relationships. CABI Publishing International, University Press. 